\title{
SCREENING AND STANDARDISATION OF BACOPA MONNIERI USED AS MEDICINE IN HOMOEOPATHY USING HPTLC METHOD
}

\author{
AMIT KHANDAGALE ${ }^{1}$ and DAMODAR SHANBHAG ${ }^{2}$ \\ ${ }^{1}$ Department of Chemistry, D. G. Ruparel College, Mahim, Mumbai - 400016, India, \\ ${ }^{2}$ Department of Chemistry, D. G. Ruparel College, Mahim, Mumbai - 400016, India.
}

\begin{abstract}
:
In this study, we have chosen HPTLC as a method of analysis to develop a standard procedure based on fingerprinting characteristics for the evaluation of homoeopathic formulations. A simple and accurate HPTLC method has been developed for the quantification of BacosideA and fingerprinting of the in-house mother tincture considered here to be a standard with that of different marketed samples available from manufacturers of homoeopathic medicines in India. This HPTLC method was quantitatively evaluated in terms of stability, repeatability, accuracy and calibration providing the utility in the analysis of the mother tincture.
\end{abstract}

Keywords: HPTLC, Standardisation, Mother Tincture, Bacoside-A, Fingerprint, MWL, Spectra

\section{INTRODUCTION:}

Bacopa Monnieri is belongs to the family of "Scrophulariaceae". It is a medicinal herb found throughout the Indian subcontinent in wet damp and marshy area [1]. It is used as traditional Indian medicine for the treatment of anxiety, and in improving intellect and memory of the several country [2,3]. In addition to the memory boosting activity, it also claimed to be useful in the treatment of cardiac, respiratory, neuropharmacological disorder like insomnia, insanity, depression, psychosis, epilepsy and stress [4,5]. It was reported to posses anti-inflammatory, analgesic, antipyretic, sedative free radical scavenging and anti-lipid peroxidative activities [6,7]. The pharmacological properties of Bacopa monnieri were studied extensively and the activities were attributed mainly due to the presence of characteristics saponins called as "bacosides" [8].

\section{MATERIALS AND METHODS}

\subsection{Chemicals and Materials:}

Authentic dried plant of Bacopa Monnieri was used to prepare the mother tincture. Bacoside- $\mathrm{A}\left(\mathrm{C}_{41} \mathrm{H}_{68} \mathrm{O}_{13}\right.$ m.p. $251^{\circ} \mathrm{C}$, purity $>99 \% \mathrm{w} / \mathrm{w}$ by TLC) was purchased from SPIC Pharma, Chennai. The solvents $99.9 \%$ absolute ethanol, dichloromethane, methanol, HPLC water were of analytical grade purity (MERCK Ltd.).

\subsection{Preparation of Standard Mother Tincture:}

The dried plant was coarsely powdered, $10 \mathrm{~g}$ of this powder was used and the requisite amount of alcohol and water was added as specified in HPI and the standard mother tincture was prepared by the percolation method. This tincture was transferred to suitable glass container and stored for further study [9].

\subsection{Preparation of Standard Bacoside-A:}

Ten milligram of Bacoside-A was weighed in a $10 \mathrm{mg}$ volumetric flask. To this $10 \mathrm{ml}$ of ethanol was added.

\subsection{Standardization of Standard Mother Tincture:}

Camag HPTLC [10] system comprising of Linomat 5 as sample applicator and TLC Scanner3 controlled by winCATS software version 1.3.4 was used for quantitative evaluation. Stationary phase used was MERCK precoated TLC Aluminium foil silica gel $60 \mathrm{~F}_{254}$ and the mobile phase used was Dichloromethane : Methanol : Water $(4.5: 1.0: 0.1) \mathrm{v} / \mathrm{v}$ [11-12]. Samples and standard were applied as $8 \mathrm{~mm}$ bands with $6 \mathrm{~mm}$ distance between the tracks. Tank saturation and plate equilibrium was given with filter paper for $10 \mathrm{~min}$. Ascending development for a distance of $80 \mathrm{~mm}$ in a twin trough chamber was completed in approximately $15 \mathrm{~min}$. Volume of standard MQ was first optimized at $6 \mu \mathrm{l}$ for fingerprinting. The $\lambda_{\max }$ of Bacoside-A was found to be $225 \mathrm{~nm}$ after taking the spectra of the standard of Bacoside-A [fig-1]. Quantitative measurement in the absorbance mode was done at $225 \mathrm{~nm}$ using a slit dimension of $6.00 \times 0.45 \mathrm{~mm}$. 


\subsection{Linearity response:}

The volume of the std. mother tincture was optimized to $6 \mu \mathrm{l}$ for quantification. It was then simultaneously applied with different concentration of standard Bacoside-A. The method was found to be linear with a regression of 0.99945 and a standard deviation of $1.82 \%$ and the amount of Bacoside-A was calculated in the mother tincture [fig-2].

\subsection{Standardisation of the standard mother tincture by fingerprint method:}

Standardisation [13] of the mother tincture was done by evaluating its fingerprint characteristics, using HPTLC method. Standard mother tincture was chromatographed simultaneously along with four other mother tinctures available in market at $6 \mu \mathrm{l}$ on the same plate for comparison [TABLE-1]. Multi wavelength (MWL) scan was done for finding the optimum wavelength for scanning. The optimum wavelength was found to be $225 \mathrm{~nm}$. The entire plate was further scanned at this wavelength for quantification and spectral match. Many fractions of std. mother tincture were matched with the help of its characteristic spectra with that of other marketed samples [fig-3]. Individual $\lambda_{\max }$ of each fraction was also found with the help of spectral scanning and then the plate was scanned with these selected wavelengths in MWL mode. The pattern of the peaks was compared for the std. mother tincture and marketed samples. It was observed that the response for various concentrations of standard Bacoside-A was linear in the range of $200 \mathrm{ng}$ to $1000 \mathrm{ng}$ with a coefficient of variation of 0.99958 and a standard deviation of $1.79 \%$ [fig-4]. Bacoside-A was quantified and the amount was calculated in individual mother tinctures. With this method we compared all available mother tinctures and the active principle was also quantified. Thus the method can be said to be standardised.

\subsection{Quantification of Bacoside-A in market samples and standard mother tincture:}

The amount of Bacoside-Awas calculated in standard mother tincture (A) and market samples (A1 to A4) and was found as given in [TABLE-2].

\section{RESULTS AND DISCUSSIONS}

The decomposition of the analyte during application or development was confirmed by two-dimensional chromatography. The chromatogram did not show any extra fractions. Repeatability of the method was checked by scanning 15 tracks of $6 \mu \mathrm{l}$ volume std. mother tincture. The co-efficient of variation (CV) was found to be 0.368 . The percentage recovery of Bacoside-A was calculated using the above method. The average recovery values obtained were $92.0 \%$ to $97.0 \%$, which confirms that the method is validated.

The HPTLC Fingerprinting characteristics of "Bacopa Monnieri" mother tinctures obtained from manufacturer (A1 to A4) and the in-house std. MQ (A) had been scanned at $225 \mathrm{~nm}$ wavelength. The scanning report as well as the fingerprint characters obtained after integration has been shown in [TABLE-1].

From the results obtained after densitometric scanning, it was observed that the Std. MQ (A) of Bacopa Monnieri shows 9 peaks. The marketed samples A1 shows 9 peaks, A2 shows 8 peaks, A3 shows 9 peaks, A4 shows 8 peaks.

Value of the four marketed tinctures (A1 to A4) was found to show minimum 8 different peaks with Rf values similar to std. MQ (A) and they are similar within themselves. So from this study it was confirmed that Bacoside-A tincture contains different components with Rf values (0.04-0.05-0.06, 0.18-0.19, 0.21-0.22, 0.27-0.28, 0.36-0.37, 0.42, 0.44-0.45, 0.48,0.49$0.50-0.51-0.52-0.53,0.76,0.78-0.79)$. These components must be considered to determine quality of any further sample of the same. Also spectral analysis indicates that spectra with particular Rf values of various components $(0.06,0.19,0.27$, $0.37,0.48,0.76$ ) have similar pattern within themselves. It may be concluded that samples procured from the market that are showing lesser peaks may not be up to the standard level.

Based on this approach our aim was to develop a standardised procedure to evaluate the mother tinctures for its accuracy, sensitivity and reproducibility. This standardisation may lead to a solution to the factors which are responsible for variation in the homoeopathic formulations. The above HPTLC method is powerful, rapid, reliable and cost effective with respect to the accuracy of the result based on both qualitative and quantitative analysis. 


\section{REFERENCES}

[1] Kapoor L. D., Handbook of Ayurvedic medicinal plants. Boca Raton: CRC Press; 1990.

[2] Singh H. K., Dhawan B.N., Neuropsychopharmacological effects of the Ayurvedic nootropic Bacopa monneira Linn. (Brahmi), Indian J. Pharmacol 1997; 29: 359-65.

[3] Singh H. K., et.al, Effects of Bacoside A and B on avoidance response in rats. Phytother Res 1998; 2:70-4.

[4] Nadkarni K.M., The Indian material medica. Columbia MO: South Asia Books; 1988.

[5] Russo A, Borrelli F., Bacopa monniera, a reputed nootropic plant: An overview. Phytomedicine 2005; 12:305-17

[6] Kishore K., Singh M., Effects of bacosides, alcoholic extract of Bacopa monniera Linn. (brahmi), on experimental amnesia in mice. Indian J Exp Biol 2005; 43: 640-5

[7] Anbarasi K. et.al, Creatine kinase isoenzyme patterns upon chronic exposure to ciagarette smoke: Protective effects of Bacoside A. Vascul Pharmacol 2005; 42: 57-61.

[8] Deepak M, Amit A, The need of establishing identities of 'bacoside A and B', the putative major bioactive saponins of Indian Medicinal plant Bacopa Monnieri. Phytomedicine 2004; 11: 264-8.

[9] Verma P. N and Vaid I.: Encyclopaedia of Homoeopathic Pharmacopoeia, B. Jain Publishers Pvt. Ltd., New Delhi; 1995, p.770-771.

[10] Sethi P.D: High Performance Thin Layer Chromatography (HPTLC), CBS Publishers, New Delhi; 1996, p.3-62.

[11] Wagner H., Bladt S. and Zgainski E.M.: Plant Drug Analysis, Springer Verlag, Berlin; 1984, p.70.

[12] Shanbhag D. A., HPTLC standardization of homoeopathic mother tinctures and comparison with products in market: Thesis, 2003, p.531-536.

[13] Raina M.K, Recent Trends in Standardisation of Herbal Materials, Indian J. of Natural Products, 1993, 9, 18-22.

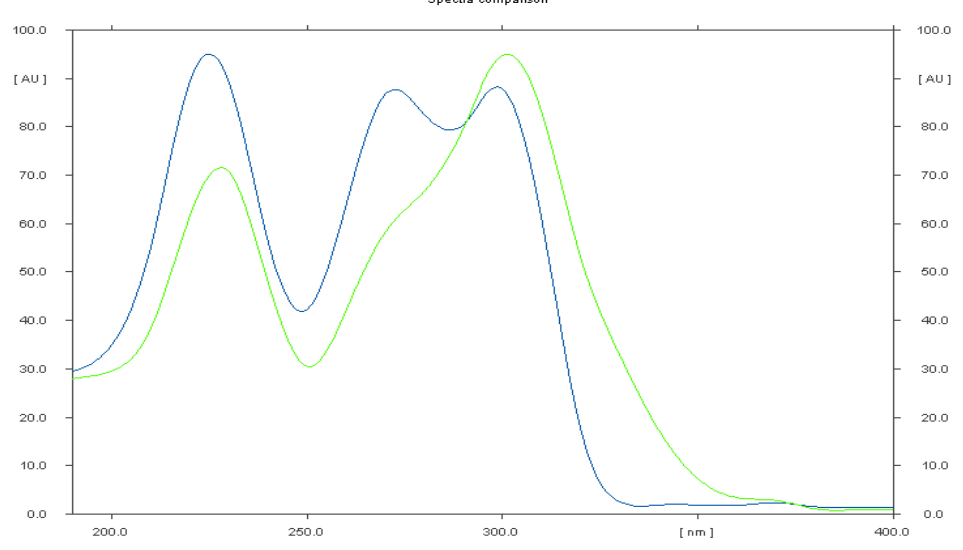

FIG. 1 ABSORPTION SPECTRUM OF STANDARD BACOSIDE-A 


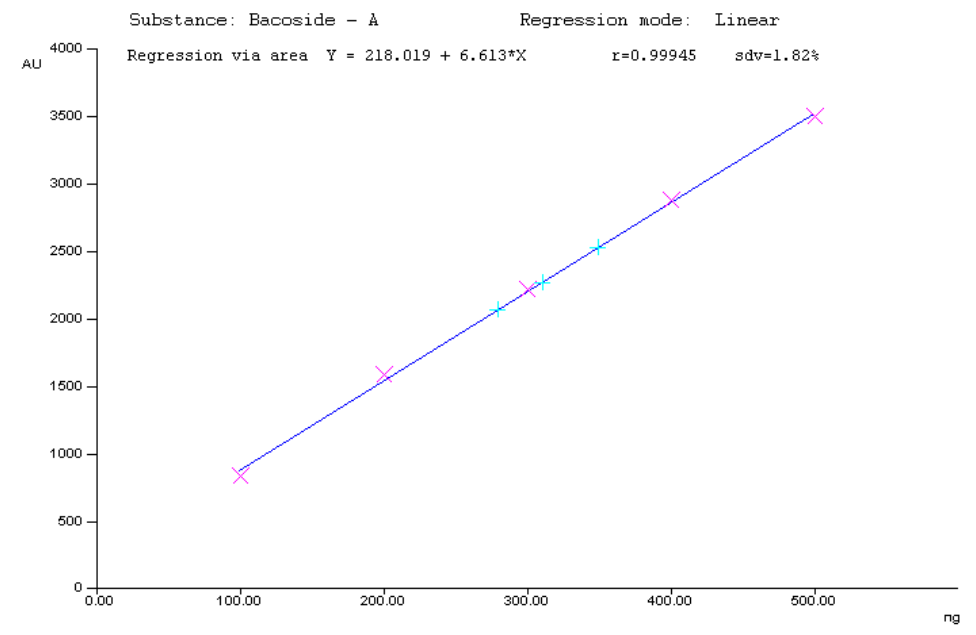

FIG. 2 CALIBRATION CURVE OF BOCOSIDE-A (AREA)

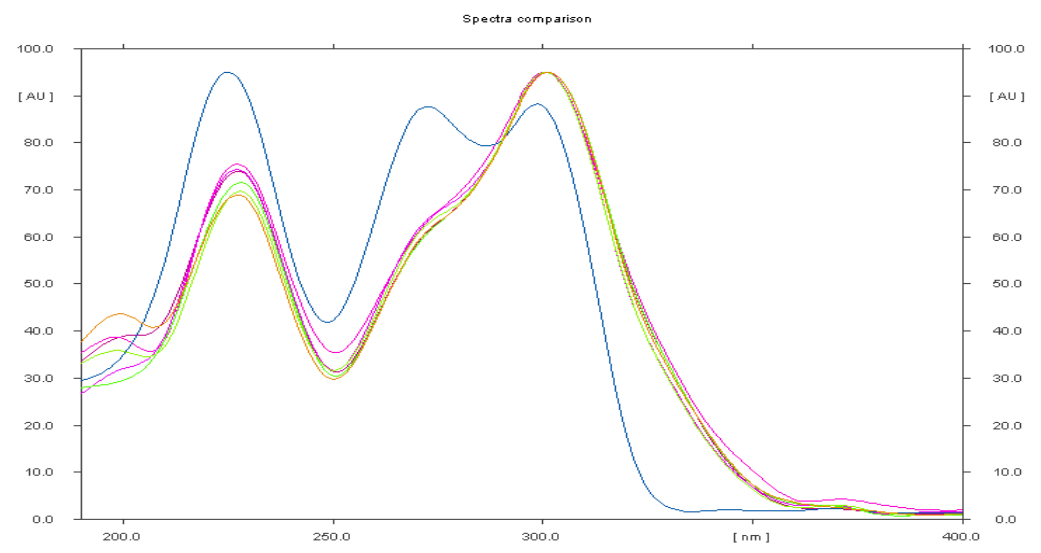

FIG. 3 OVERLAY OF ABSORPTION SPECTRA OF STANDARD, STANDARD MQ AND MARKETED SAMPLES

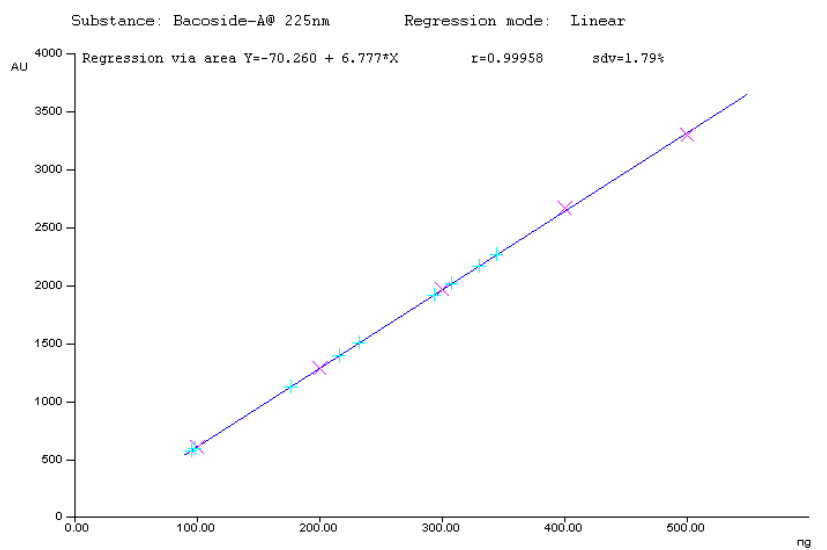

FIG. 4 CALIBRATION CURVE OF BACOSIDE-A 
IOSR Journal of Pharmacy

Vol. 2, Issue 1, Jan-Feb.2012, pp. 052-056

\begin{tabular}{|c|c|c|c|c|c|c|c|c|c|c|c|c|c|c|c|}
\hline Peak & \multicolumn{3}{|c|}{$\mathbf{A}$} & \multicolumn{3}{|c|}{$\overline{\mathrm{A1}}$} & \multicolumn{3}{|c|}{ A2 } & \multicolumn{3}{|c|}{$\overline{A 3}$} & \multicolumn{3}{|c|}{$\overline{A 4}$} \\
\hline & Rf & $\begin{array}{c}\text { Max. } \\
\text { Ht. }\end{array}$ & $\begin{array}{c}\% \\
\text { area }\end{array}$ & Rf & $\begin{array}{c}\text { Max } \\
\text { Ht. }\end{array}$ & $\begin{array}{c}\% \\
\text { area }\end{array}$ & Rf & $\begin{array}{c}\text { Max. } \\
\text { Ht. }\end{array}$ & $\begin{array}{c}\% \\
\text { area }\end{array}$ & Rf & $\begin{array}{c}\text { Max. } \\
\text { Ht. }\end{array}$ & $\begin{array}{c}\% \\
\text { area }\end{array}$ & Rf & $\begin{array}{c}\text { Max. } \\
\text { Ht. }\end{array}$ & $\begin{array}{c}\% \\
\text { area }\end{array}$ \\
\hline 1 & 0.06 & 23.5 & 2.70 & 0.05 & 83.8 & 6.12 & 0.04 & 17 & 1.51 & 0.05 & 29.8 & 2.08 & 0.05 & 27.6 & 1.61 \\
\hline 2 & 0.18 & 10.2 & 1.76 & 0.18 & 26.3 & 1.42 & 0.18 & 14.1 & 1.21 & 0.19 & 70.1 & 10.29 & 0.18 & 26.1 & 2.43 \\
\hline 3 & 0.22 & 14.7 & 2.63 & 0.21 & 52.1 & 4.95 & 0.22 & 33.2 & 6.34 & 0.27 & 41.3 & 7.06 & 0.28 & 37.7 & 4.95 \\
\hline 4 & 0.28 & 12.7 & 2.34 & 0.36 & 365.1 & 39.59 & 0.27 & 24 & 2.92 & 0.36 & 150.3 & 24.98 & 0.37 & $\begin{array}{c}428 . \\
7\end{array}$ & 59.36 \\
\hline 5 & 0.37 & 217.2 & 47.95 & 0.42 & 50.2 & 4.81 & 0.36 & 343.9 & 50.57 & 0.44 & 38.3 & 9.13 & 0.44 & 38.2 & 6.45 \\
\hline 6 & 0.45 & 27.6 & 7.50 & 0.44 & 40.6 & 2.63 & 0.48 & 96.3 & 15.81 & 0.49 & 47.5 & 8.54 & 0.49 & 82.1 & 13.13 \\
\hline 7 & 0.50 & 42.5 & 10.13 & 0.49 & 94.4 & 11.31 & 0.51 & 33 & 4.81 & 0.52 & 31.7 & 5.44 & 0.61 & 14.6 & 2.22 \\
\hline 8 & 0.53 & 27.9 & 5.32 & 0.52 & 48.9 & 6.09 & 0.78 & 56.2 & 17.46 & 0.59 & 11.8 & 2.68 & 0.79 & 35.4 & 9.85 \\
\hline 9 & 0.79 & 39.7 & 19.66 & 0.76 & 115.0 & 23.08 & - & - & -- & 0.76 & 91.9 & 29.79 & - & - & - \\
\hline
\end{tabular}

TABLE - 1 : ANALYSIS OF DIFFERENT BACOPA MONNIERI MOTHER TINCTURES AT SCANNING WAVELENGTH 225 NM

\begin{tabular}{|c|c|c|}
\hline Sr. No. & Name of sample & Wt. of Bacoside-A in 100 ml sample \\
\hline 1. & A & $5.41 \mathrm{mg}$ \\
\hline 2. & A 1 & $8.43 \mathrm{mg}$ \\
\hline & & \\
\hline 3. & A2 & $1.57 \mathrm{mg}$ \\
\hline & & \\
\hline 4. & A3 & $4.82 \mathrm{mg}$ \\
\hline 5. & A4 & $2.82 \mathrm{mg}$ \\
\hline
\end{tabular}

TABLE - 2 : AMOUNT OF BACOSIDE-A IN BACOPA MONNIERI MOTHER TINCTURES

A- Standard mother tincture of Bacopa Monnieri prepared in our laboratory.

A1 - A4 - Four samples of Bacopa Monnieri tincture from manufacturer.

Rf corresponds to maximum peak height. 